\title{
THE (UN)INTENDED OUTCOME OF PERFORMANCE MEASUREMENT IN THE PUBLIC SECTOR
}

Andy Adcroft (University of Surrey) and Robert Willis (Anglia Polytechnic University)

\section{$\underline{\text { Abstract }}$}

\section{Purpose}

To consider the extent to which (a) regimes of performance measurement in the public sector are fit for purpose and (b) the likely outcomes for public services and public sector workers of such performance measurement systems.

\section{Design/Methodology/Approach}

The article considers 4 key issues: The context and content of performance measurement in the public sector; the specific examples of healthcare and higher education; the limitations of performance measurement systems; the likely outcomes of performance measurement systems.

\section{Findings}

Current systems of performance measurement in the public sector are unlikely to have a significant influence on improving services. The most likely outcomes of these systems is further commodification of services and deprofessionalisation of public sector workers.

\section{Originality/Value}

The articles builds on established literature and offers a systematic metaphor-driven critique of performance management in the public sector and discusses the implications of this.

\section{Key Words}

Performance Measurement

New Public Management

National Health Service

Higher Education

Commodification

Deprofessionalisation 


\section{Introduction}

This article argues that the most likely outcomes of increased usage of performance measurement regimes in the public sector is the commodification of services which will be delivered by an increasingly deprofessionalised public sector workforce. The article argues that this is the most likely set of outcomes for two reasons. First, there are a series of technical and managerial issues with standard public sector performance measurement systems which make them unfit for purpose. Second, there are a series of difficulties in importing management practices from one context to another, in this case from the private into the public sector.

In suggesting these outcomes, the article will present a reasonably logical set of arguments. Thus, the article is organised as follows. The first section considers the context of performance measurement in the public sector through a discussion of New Public Management (NPM) and argues that performance measurement is an increasingly common phenomenon across many elements of the public sector both nationally and internationally. The second section considers two specific examples of performance measurement in the UK's National Health Service (NHS) and higher education sectors. Having considered both the context and content of performance measurement in the public sector, the third section of the article discusses a number of key weaknesses of such regimes and argues that these weaknesses have resulted in systemic problems which make the regimes unlikely to deliver real benefits in terms of actual service improvements. Finally, the article considers other outcomes of such systems and considers some implications for both services and those who deliver them.

\section{Measuring Performance in the Public Sector: Context and Rationale}

Analysis without context can be meaningless and so, before discussing specific issues and examples of performance measurement in the public sector, it is important to place current regimes of management in the public sector into a wider (recent) historical context. This raises the concept of New Public Management (NPM). Whilst there may be no strict definition of NPM that is universally accepted, it is valid to suggest that the concept is a reflection of a number of different trends. For example, Hood (1991, pp 4-5) suggests that NPM consists of a number of different doctrines which are blended and mixed according the specific public sector circumstances under discussion. These doctrines include more emphasis on "professional" management, the introduction of explicit measures of performance, a focus on outputs and results and an ever greater role played by "private sector styles" of management practice. Furthermore, in discussing changes in the public sector over the past two and half decades, Pollitt (2003) provides illustrations of how these doctrines have manifested themselves in specific changes and draws attention to privatisation, contracting out and reforms such as the internal market in the NHS. The outcome of these doctrines and reforms has been the creation of a new set of principles which govern practices in the public sector; Ferlie and Steane (2002) suggest that all this boils down to "managers, markets and measurement" (p. 1461).

One of the recurring themes of NPM as both practice and theory is the importation of practices into the public sector from elsewhere. This importation takes two general forms and, whilst it is possible to consider them separately, we would also make the point that there is significant overlap between them. The first form of importation is international as public sectors in one country import practices from public sectors in another; Hood (1991, p. 3), for example, suggests that NPM as whole is a reaction to the "development of an international agenda" for public sector management. More specifically, Walshe (2001) draws attention to the UK's approach of learning from the USA about healthcare management and suggests that this 
occurs because of the similarities internationally in the challenges facing healthcare professionals such as rising costs, technological change and growing public expectations. Similarly, Ferlie and Steane (2002) suggest a set of common characteristics in public sector management across western Europe, north America and Australasia with benchmarks and quality standards becoming commonplace. In drawing conclusions about this trend, Walshe (2001, p.31) sounds a note of caution and suggests that "the unthinking and uncritical adoption of bright ideas from other countries ... is foolhardy at best."

The second form of importation, and the central issue for this article, is that of private sector management practices finding currency in a variety of public sectors across the world, with a focus on the UK. Hood (1991, p. 5) suggests the commonality of this approach by arguing that NPM in general represents the marriage of "administrative reform" with "business type managerialism". More recently, McNulty and Ferlie (2002) have considered the experience of the NHS in adopting Business Process Reengineering (BPR) and are sceptical about the extent to which this form of private sector management has really transformed the way in which the NHS operates and is managed. Ferlie and Steane (2002) examine the issue more broadly and conclude that the adoption of private sector practices has, to many intents and purposes, blurred the distinction between public and private sectors where the government's role has become much more of a facilitator of services compared to the front line provider of services. The article will now turn to examine the rationale for such importation from non-public sector organisations.

Central to pretty much all measures of organisational performance is an understanding of the relationship between economic inputs and outputs. Performance as measured by such mechanisms as labour and capital productivity, return on investment, customer satisfaction, service quality and all the rest are simply different means to the same ends; what does the organisation get out for the investment put in? Whilst discussion of performance measurement starts with this simple and basic notion, the problem is that the process through which assessment is made is usually complex. Williams et al. (1993), for example, in examining comparative productivity performance between Japanese and American car assemblers, argue that the problem of complexity manifests itself because performance is affected as much by market conditions, industry structures and social settlements as it is by purposive management action.

Preoccupations with performance measurement, however, are clearly built on the assumption that it will bring real and tangible benefits to organisations. Meyer (1994, p. 101) suggests that performance measurement is useful in so far as it can "tell an organisation where it stands in its effort to achieve goals" but also points out that it is less useful in explaining "what it should do differently". This point notwithstanding, other authors suggest a legion of benefits to be gained from good performance measurement and objective setting. Drucker (1995, p. 23) discusses the benefits in terms of generating new and additional resources, clearer understandings of economic chains, wealth creation and as both the "creatures and creators of a material environment in which opportunities lie". Equally prosaically, Kaplan and Norton (1992, p. 124) in discussing the balanced scorecard, suggest the benefits are in the translation of the "company's strategy and mission statement into specific goals and measures" which allow for, amongst other things "products to market sooner and innovative products tailored to customer's needs". If there are organisational benefits at the strategic level, there are also benefits further down the organisation's food chain; "the average quality of decisions made day in day out will be vastly higher than before. When that happens you can bet the company's performance will show it' (Ness and Cucuzza, 1995, p. 70). 
If the benefits of setting objectives and measuring performance provide the rationale for management action, the next logical step in the discussion is to consider the processes involved in that management action. As Williams et al. (1993) have pointed out, albeit in a different context, the management response will depend on the interpretation of the measures and targets; accountants will call for new financial systems, engineers for new technology, personnel managers for more training and so on. The literature suggests a wide variety of management options from, for example, strategic processes drawn out of the balanced scorecard (Kaplan and Norton, 1992), improved management of teams (Meyer, 1994), return on management activities (Simons and Davila, 1998), ABC activities (Ness and Cucuzza, 1995), the performance management manifesto (Eccles, 1991) and so on. For the purposes of this article what is important is the translation of these principles into a public sector context. After all, as Drucker (1995, p. 23) argues "what is important is not the tools. It is the concepts behind them".

Measuring the performance of the public sector through private sector practices and principles is hardly a new or recent idea; in many ways the origins of the modern regimes of assessment lie in the 1980s and the early work of the Audit Commission (Local Government Finance Act, 1982). With an early emphasis on the performance of local authorities in the UK, the work of the Audit Commission is important not only in terms of its managerial legacy but also as a tracking device to assess how structures have changed (Power, 1987). The Audit Commission began with a problem definition which stated that public sector (under) performance was a product of (poor) public sector management and the solution to these problems was the creation of frameworks which mimic the private sector (Audit Commission, 1988, Banham, 1987). In response to this specific problem definition, the public sector has, for example, been subjected to increased competition through compulsory competitive tendering and the imposition of quasi-competition through internal markets and best value systems. The broad managerial context for these changes was the need for public sector organisations to become more strategic in their behaviour with the need for, for example, "corporate vision" and "a shared culture" (Audit Commission, 1986, p. 15).

Lawler and Hearn (1995, p. 9) argue that this kind of public sector managerialism "implies that there are certain core functions of management applicable across all organisational contexts and that certain management techniques can be transferred across contexts - in this case, from the private to the public sector". This is broadly representative of the view that the current relationship between public and private sectors is about transferring practices from one sector to the other (Adcroft and Willis, 2002). Holloway et al. (1999) suggest that one of the main examples of this transfer is in the increased importance attached to benchmarking in the public sector; two-thirds of managers in the education and health sectors are involved in benchmarking of some sort or another. On this issue, Drucker (1995) argues that benchmarking is built on the assumption that "what one organisation does, any other organisation can do as well". This rationale is followed through in a process based around measuring existing performance, comparing that performance to either an industry or market leader or some desired performance in the future, analysing the causes of differences in performance before implementing management actions to bridge the gap, often through emulation.

In the specific example of the NHS for example, the rationale for benchmarking (and the associated regimes of performance measurement which are a necessary requirement for benchmarking) is focused on the "significant variations in clinical practice between clinicians 
and institutions" (Walshe and Sheldon, 1998, p. 15). Overall, this will "encourage greater benchmarking of performance in different areas, and the publication of comparative information will allow people to compare performance and share best practice" (NHS Executive, 1998, p. 6 ). Thus, whilst the intention is to make "quality and effectiveness central to performance measurement", the logical argument to make is that this (laudable) aspiration can only come to fruition if the regime of performance measurement is fit for purpose. Holloway et al. (1999, p. 352) raise some important qualifications for the use of benchmarking and performance measurement as effective management tools in this respect and suggest that this effectiveness depends "on taking a relatively holistic approach" where all elements of interaction, especially "softer" (and therefore harder to measure) aspects are "fully appreciated before changes are proposed". The article will now consider two specific examples of performance measurement and the extent to which they are fit for such purposes.

\section{Examples of Performance Measurement: The NHS and Higher Education}

This section considers two specific examples of performance measurement; waiting list targets in the NHS and the assessment of the quality of the student experience in higher education. In choosing these examples there are 2 central issues which must be addressed. First, to what extent do these examples accurately illustrate changes across the public sector in general? Second, do these examples have some degree of international currency or are they just specific to the UK?

The central difficulty in measuring the performance of all organisations is complexity: Organisations are complex in so far as they are collections of visible and invisible, tangible and intangible elements and performance itself is determined by a multitude of different internal and external factors and conditions. We would suggest that the broad approach in the public sector to this problem is centred on deconstruction. Organisations are broken down into discreet elements of assessment such as departments, functions or services which can then be deconstructed into ever smaller elements of output as and when necessary. These elements are then subjected to a rigorous process of performance measurement in order to compare performance across different areas, share best practice, monitor the use of resources and so on. For example, Kirkpatrick and Ackroyd (2003, p. 518) argue that this process in social service departments is aimed at providing "mechanisms for ensuring control and accountability" and in public housing, Sprigings (2002, p. 11) highlights the importance of "performance indicators and business disciplines" under NPM regimes. Furthermore, in discussing proposed changes to management systems in the fire service, Gilchrist (2003, p. 214) discusses the introduction of performance targets and Bovaird and Davis (1999, p. 307) point out that local authorities are forced to make use of "performance measurement and management systems as a way of evaluating their performance".

We would, therefore, suggest that the two examples which follow are illustrative of wider changes across different elements of the public sector in the UK and we would also make the realistic claim that they illustrate changes at an international level. Christensen and Yoshimi (2001, p. 271) suggest that "performance reporting has received increasing attention" in the Japanese and Australian public sectors and Bevir et al (2003) draw out differences in policy between the USA and western Europe but argue that these differences should not hide similarities in the principles behind the policies. Similarly, Schested (2002) suggests similar outcomes for professional status across western European countries that have embraced NPM and Norman (2004, p. 429) suggests the New Zealand experience of NPM has created "an array of focused providers of service and policy outputs" in which performance measurement 
has played a central role. The literature, therefore, would suggest that the exhibits are broadly illustrative of wider changes across different elements of the public sector nationally and internationally.

\section{Exhibit \#1: The NHS: resources and strings}

"cut NHS waiting lists by treating an extra 100,000 patients as a first step by releasing $£ 100$ million saved from NHS red tape" (Labour Party, 1997, p. 8)

The reduction in NHS waiting lists grabbed all the headlines as it was one of the 5 key pledges made by the incoming government in 1997. It must, though, be recognised that this was just one element, albeit a reasonably indicative one, of a wider policy of reform towards the NHS. The reform of health care in the UK was built on the notion that the NHS had not been subject to sufficient change in the preceding decades. According to this problem definition, the NHS has "systematic problems, which date from 1948 when the NHS was formed" (Department of Health, 2000, p. 2). In particular this broad problem definition focused on 4 key characteristics of the service that required change: There was a lack of national standards; there were too many old fashioned demarcations between staff and barriers between services; there were no clear incentives and levers to improve performance and, as a whole, the service was overcentralised and patents were disempowered.

Turning the NHS around will happen through the creation of a new model which still conforms to Aneurin Bevan's principle of being free at the point of use but with some modern characteristics such as new national standards of health care, more plurality in the numbers and types of providers, more patient choice and the ubiquitous shorter waiting times. In this context, the transformation starts from the a priori assumptions that there are major problems of under-funding caused by long term financial neglect and there are major problems of undermanagement, hence the need to change the way the service is run (Department of Health, 2000). Thus the solution to the problem definition is based on a combination of increased funding and managerial reform; resources with strings attached. We will turn to examine resources first.

Wanless (2000, p. 4) argued that "the UK must expect to devote a significantly larger share of its national income to healthcare over the next 20 years" and only if this happens can the UK hope to catch up with the standards of healthcare offered in other European countries. Therefore, the initial aim is to reach the European average of $9.4 \%$ of GDP spent on healthcare by 2008 which will involve annual increases in health spending of about $7.5 \%$ (The Treasury, 2002a). In the longer term, government plans are to increase spending over the next 20 years by between 4.2 and $5.1 \%$ annually in real terms.

We now turn to consider the strings that have been attached to this financial largesse. Managerial reform in the NHS follows the typical strategy, policy, tactics model of rational decision making: At the strategic level, clearly defined aims and objectives are determined; at the policy level, choices are made as to how these aims and objectives will be met and, at the tactical level, these plans and policies are implemented. This exhibit will focus on NHS decision making at the strategic and policy levels.

Strategic objective setting in the NHS is reflective of many things, not least the power of The Treasury in both economic and social policy making. The major string attached to the increasing resources comes from the NHS Public Service Agreement (PSA) through which the 
Secretary of State for Health is directly accountable for performance to the Chancellor of the Exchequer: "In each area of service delivery ... we are tying new resources to new reform and results, developing a modern way of running good efficient public services ... the public can access the information" (The Treasury, 2002b, p. 3). From the PSA, three objectives are paramount: First, there should be improvements to service standards assessed by clear and measurable outcomes such as waiting lists, access to primary care and accountability; Second, health and social care outcomes for everyone should be improved with measurables such as mortality rates and teenage pregnancies; Finally, the service should deliver value for money through 1-2\% productivity and service improvements every year (The Treasury, 2002b).

Clearly there is more to strategy and transformation than objective setting - judgement about the efficacy of any activity is based on what it actually achieves rather than on what it is supposed to achieve. The delivery of the objectives underpinning NHS reform will come from the NHS Plan which fully accepts the strings attached to the resources; "investment has to be accompanied by reform" (Department of Health, 2000, pp 3-5). These reforms will take a number of different forms. There will be more joined up services, for example; "social services and the NHS will come together". New working practices will form the basis of the $21^{\text {st }}$ century NHS through new contracts for doctors and extensions to the role and duties of nurses, patients will have more input into NHS decision making and there will be more use of private resources (Department of Health, 2000).

There is a clear and underlying logic to NHS reform; in the language of management it offers a consistent and coherent process. The process is centred on tangible and measurable outcomes which provide the rationale for the changes in management that are taking place and the basis of judgement as to whether those changes in management are successful. The PSA and the NHS Plan together provide a neat blend of the carrot and the stick. The carrot is provided through such things as increasing autonomy as "local NHS organisations that perform well for patients will get more freedom to run their own affairs" (Department of Health, 2000, $p$. 4) and the stick is provided as it will become easier to compare and contrast performance across different sections of the service and, where there is underperformance, "the government will intervene more rapidly in those parts of the NHS that fail their patients" (Department of Health, 2000, p. 10).

\section{Exhibit \#2: Subject Review: all things to all people}

"The Agency's mission is to promote public confidence that quality of provision and standards of awards in higher education are being safeguarded and enhanced" Quality Assurance Agency for Higher Education, 2002, p. 1.

Higher education offers an interesting and specific challenge for public sector management; how to maintain the quality of a service that is subject to ever increasing demand and take-up at the same time as units of resource are being diminished. For example, between 1998 and 2002, the number of new enrolments into higher education institutions increased by over onefifth and the total number of students studying in higher education increased by over $6 \%$. Whilst these figures suggest significant drop out rates, we would wish to avoid the debates about the implications of widening access and, instead, examine one of the key measurement processes through which this is managed. Thus the case study focuses on the Subject Review process and the role of the Quality Assurance Agency for Higher Education (QAA). 
Notwithstanding the possibly pedantic point that the aim of the QAA is to ensure public confidence in the quality of higher education rather than to assure the actual quality of higher education, the subject review methodology differs in two substantial ways to the measurement regimes imposed elsewhere in the public sector. First, measurement is not based on Whitehall diktat but is determined by the institutions being measured; the methodology is developed around assessment of the institutions ability to meet its own aims and objectives. Second, the process of measurement is carried out through peer review; whilst some elements of the process are based on bog standard number crunching, other elements are less obvious and apparent and, therefore, require some kind of academic judgement. Against the backdrop of these principles, the purpose of subject review is to "secure value from public investment", "encourage improvements to the quality of education" and "provide ... accessible public information" (QAA, 2000, p. 2).

The process involves breaking down higher education provision into a number of different compartments from the broad macro-level to the micro-level until a final measurement drops out. Overall, higher education in the UK is broken down into subject compartments; by the end of 2001, for example, 11 discreet subject areas had been through the review process. Each subject component is then considered on an institution by institution basis which means that provision is assessed across a number of different levels in institutions from, for example, HND through to Masters degree. Within institutions, the overall provision in an institution is compartmentalised into six aspects of provision which cover the whole of the student experience from initial application through to graduation, further study and employment. Finally the aspects are placed into a grading compartment depending on the extent to which aims and objectives have been met.

At the core of the subject review process are the six aspects of provision. Combined together, these aspects work as a sort of higher education value chain which judges the quality of transformation from student input to graduate output. Using this value chain analogy, we can define the primary activities as Curriculum Design, Content and Organisation (CDCO), Teaching, Learning and Assessment (TLA) and Student Progression and Achievement (SPA). CDCO primarily deals with the content of the provision and the extent to which it is, for example, up to date, coherent and driven by learning outcomes. TLA is concerned with the delivery of the curriculum; what happens in the lecture theatres, seminar rooms and examination halls, again with an emphasis on coherence through a clearly articulated strategy. SPA is the only real numbers driven element of the review process and measures, amongst other things, the popularity of programmes, demographics of the student population, progression through different levels of study, graduation rates and employability. Supporting these primary activities are three further aspects: Student Support and Guidance (SSG), Learning Resources (LR) and Quality Management and Enhancement (QME). SSG considers all elements of support that students may need during their studies from academic guidance through pastoral welfare and onto careers advice. LR considers the availability within the provision of things like library resources, teaching accommodation, IT and administrative support. Finally, QME covers two key issues: how quality is assured within the provision and how quality is enhanced within the provision.

The outcome of subject review is not a score; the provision within an institution does not get a final mark. Instead the outcome of a review is a profile of grades across each aspect of provision. This may seem like another pedantic point, given that it is common practice across the sector to view the outcome of the process in this manner, but the important point should not be lost that this is an unintended outcome. Each aspect of provision achieves a grade from 4 
where the aspect makes a full contribution to the achievement of aims and objectives down to a 1 where aims and objectives are not met. The graded profile is significant because of the use made of subject review grades. For example, a grade of 1 in any aspect of provision results in a further review within 12 months and three or more aspects graded at 2 requires the institution to produce an improvement plan.

Against a backdrop of increasing demand and reductions in the unit of resource, the subject review process attempts to deliver for a number of different stakeholders. For the government and the QAA the process attempts to ensure that available resources are used effectively; despite increasing demand for and take-up of higher education there should be no reduction in the quality of higher education. For the student stakeholder the aim is to convince about the value of qualifications earned in higher education and to allow for more informed decision making as to which programmes and institutions offer the best value. For the professionals in higher education, the aim is to balance the need for things like accountability against the desire for academic freedom through a system of measurement carried out by respected peers and assessed against criteria determined by those being assessed.

\section{Problems with the Measurements: Metaphors}

Having considered the two examples of performance measurement systems, which reflect wider policies and practices both nationally and internationally, we now turn to consider the extent to which this approach is fit for purpose. The fundamental question centres on the extent to which it is likely that these type of systems will deliver significant improvements in performance across the various services to which they are applied. Our conclusion is that this is unlikely as there are a number of systemic problems with this approach to service improvement.

Problem 1: as services are broken down and deconstructed into ever smaller components, the less the performance of the whole service is being measured. In making a judgement as to the value of a piece of music, for example, analysis is not carried out on a note by note basis but rather on how the notes fit together; on a note by note basis all pieces of music would be the same; Mozart's C sharp is exactly the same as Andrew Lloyd Webber's. Similarly, we would argue that much public sector provision should be treated in a gestalt manner where the overall quality of the provision is determined by how the individual elements fit together. For example, Subject Review in higher education actually militates against taking an overall view of the student experience; the outcome of the review is six individual grades for the aspects of provision and not, despite common practice, an overall mark out of 24 .

Problem 2: measurement can be the cause of uncertainty as much as certainty about overall performance because the individual elements measured are rarely independent of one another. Gore Vidal's maxim that "it is not enough to succeed, others must fail" illustrates many of the problems in the public sector where resource constraints are still a fact of life. Improved performance in one area may well be the result of a retargeting of resources which, ceteris paribus, means worsening performance elsewhere. For example, in the NHS, poor performance in certain elements of preventative treatment maybe the result of improved performance in other elements of the service such as waiting lists.

Problem 3: scientific approaches to measurement assume objectivity achieved through dispassionate analysis of the available evidence but subjective interpretation of the evidence is often the case. Is a glass half full or half empty? Where the process of measurement involves 
professionals from the field under measurement, it is impossible to get an absolutely objective measurement. For example, in considering the quality of curriculum design and delivery in higher education subject reviewers will inevitably be influenced by their own intellectual and pedagogic preconceptions. Where much of the analysis of the student experience is based on the assessments of those directly involved as deliverer and participant, it is dubious as to whether the subjectivity of this information can always be objectively screened out.

Problem 4: the use of the results of performance measurement in league tables assumes that all those being measured start from the same point. There are usually more sources of difference between same-service providers than there are similarities. In "Animal Farm" the final rule of the farm was that all animals are equal; all the four legged characters started from the same position and had equality of access to the farm's resources and structures. One of the key messages of the allegory, however, was that whilst all animals are equal, in reality some are more equal than others. Performance is determined by a whole series of internal and external factors from the entry qualifications of undergraduate students to the socio-economic conditions faced by the local hospital. Educating undergraduates at universities with high levels of available resources offers fundamentally different challenges to educating undergraduates when resources are in limited supply just as providing healthcare in affluent areas is different to providing healthcare in areas where poverty is endemic. These differences are rarely, if ever, reflected in league tables.

Problem 5: in any complex process of service delivery there will always be elements of that service which are beyond scientific measurement. In such cases, proxies are used whose relationship to the thing being measured can often be tenuous. Incensed with the vanity and folly of the court in the $17^{\text {th }}$ century, Jonathon Swift wrote Gulliver's Travels not as a children's adventure story but as piece of political satire. In making his point, and wishing to avoid persecution, Swift chose the vehicle of Gulliver and the mythical lands of Lilliput, Brobdingnag and the others because some things just could not be said. Similarly, some things cannot be measured but the dominance of scientific approaches demands that measurements are made of the next best thing using some kind of proxy. For example, measuring the extent to which students are supported through their studies in higher education is difficult and so the proxy of access to support mechanisms is used regardless of the efficacy of those mechanisms.

Problem 6: the choice of targets and performance measurements can be used to cynically influence the results of measurement. In boxing it is called building a record. Young prospects no longer achieve their shot at the title by taking on all comers and improving but rather through the careful selection of opponents; the next fight is chosen, not necessarily because the fighter represents an incrementally better opponent but because they can be beaten. The choice of what and how something is measured can often be about creating an impression of improvement rather than delivering any real improvement. The success of initiatives which are, for example, tough on crime often depends on which crimes are chosen to be tough on and, in any case, measures which are tough on the causes of crime are given less attention because they are, by their nature, less quantifiable and more ambiguous. Additionally, in higher education, the subject review process makes it difficult to differentiate between activities which are driven by objectives and objectives which are born out of activities.

\section{(un)Intended outcomes: Commodification and deprofessionalisation}

Ferlie and Steane (2002, p. 1462) offer a continuum based analysis in order to explain the changes bought about internationally by the embracing of NPM. They argue that whilst only 
one country in their sample, New Zealand, has seen change occur on a massive scale, in the majority of cases NPM has resulted in "substantive" changes across public sectors in countries such as the UK, Canada and Australia. This section of the article considers further the effects on NPM, through the central mechanism of performance measurement, on the public sector. Given the weaknesses in the regimes of performance measurement highlighted in the previous section, we are obviously sceptical about the extent to which actual performance can be improved through this kind of intervention and so will focus instead on what we see as the most likely, perhaps unintended, outcomes. Our argument is that the increased use of performance measurement and the importation of private sector management principles and practices will have the dual effect of commodifying services and deprofessionalising public sector workers. As per our earlier discussion, we would also suggest that these outcomes will not be limited to just the two exhibits presented earlier but will have wider applicability across both national and international sectors.

We would define commodification in terms of the transformation of relationships into quasicommercial relationships with an emphasis placed on the economic activity of buying and selling and the management activity of performance measurement. This could manifest itself, for example, in the commercialisation of activities such as research in higher education institutions where there is an increasing focus placed on "harnessing knowledge to wealth creation" (Department for Education and Skills, 2002, p. 12). At a more micro-level, Lincoln (1998, p. 263) notes the American experience where researchers are forced to "consider their work as a form of commodity" but also draws attention to the commodification of society in general. This could manifest itself in the commercialisation or corporatisation of organisations previously exempt from business pressures. Again the American experience may be instructive; Altheide (1987, p. 619) argues that the process inevitably spreads to all non-profit organisations that are forced to adopt "business processes and ideas".

If the process is one of commodification, then the outcome must inevitably be the resolution of "worth into exchange value" and the conversion of "the physician, the lawyer, the priest, the man of science, into paid wage labourers" (Marx and Engels, 1848, p. 56). This we would broadly categorise as deprofessionalisation. Weber (1927) distinguishes the professional through the rationalisation process involved in making decisions and this is further developed by Ritzer and Walczak (1988, p. 4) who define a professional as someone whose activities are value driven where the crucial values are "altruism, autonomy and authority". Transformation through commodification changes the basis of decision making such that values become much less important than the rules, regulations and performance measures of the organisation. For example, Bottery and Wright (2000) argue that a mixture of market initiatives and increased central control has fundamentally changed the nature of teaching as a profession and Ritzer and Walczac argue that there has been a substantial "decline in the ability of the medical profession to distinguish itself from bureaucrats and capitalists" (p. 1).

The root cause of these outcomes is the importation of inappropriate principles and practices into the public sector, we reject Drucker's earlier argument that what works in one organisation must automatically work in each and every other. There are fundamental differences between public and private sectors which will always serve to limit the efficacy of the practices transferred. Pollitt (2003, p. 24), for example, suggests that the public sector is different because of the context in which management decision making is made; unlike many private sector organisations, public service providers must be explicit in their displays of "equity, impartiality and a certain moral enlightenment" which results in a clear "ethical distinctiveness". The line of argument presented in this article leads us to conclude that when such ethical 
distinctiveness is lost, commodification and deprofessionalisation occur which must necessarily have implications for all stakeholders.

Across different sectors there is some ambiguity in evidence and so any conclusions must be suggestive and tentative rather than dogmatic and certain. In the NHS, for example, Ferlie et al (1996) suggest that the changes and practices discussed may have served to increase the autonomy of healthcare professionals and they dismiss the idea of a uni-directional shift in power towards managers; NPM and all that it entails is not necessarily about the creation of something new but rather may be about the accommodation of new ideas and processes in an existing system. On the other hand, Walshe and Sheldon (1998, p. 18) suggest that the impact of NPM has been to "limit the extent to which clinical autonomy is seen as acceptable". In higher education the evidence suggests a slightly clearer outcome. For example, Deem (2004, p. 116) srgues that universities have become "more akin to a business than an educational institution" and questions "whether the contemporary UK university can survive the domination of management" over academic leadership (p. 125). Talib (2003) makes the point that under these conditions it is inevitable that there will be some sort of shift away from "professional activities" which may have a high social worth or intrinsic value towards those activities which are management driven. Kirkpatrick and Ackroyd (2003) suggest that whilst all this may improve the accountability of service providers there is no guarantee that it will improve the quality of services.

\section{Conclusion}

In drawing together the arguments and evidence presented in this article, it is probably a worthwhile exercise to ask 'who benefits'? Is a certain degree of professional pain a reasonable price to pay if there are real improvements to services or if scarce resources are allocated in a more effective manner? Whether intended or unintended, we would argue that it is highly unlikely that the outcomes of NPM and performance measurement will be significant gains for any of the crucial stakeholders in public service provision. If the public sector is going to continue to import private sector practices then it is only reasonable to import the lessons of such practices at the same time. Kaplan and Norton (1992, p. 184), for example, point out that "an organisation's measurement system strongly affects the behaviour of managers and employees" which is a slightly obvious point to make given the two and half decades of attempts to remake the public sector in the image of the private sector. If performance measurement changes behaviour in a beneficial way then it may be a price worth paying. However, experience of such systems of measurement outside of the public sector suggest a less than optimum outcome where the struggles within organisations are not traded off by gains for customers outside the organisation. On the issue of performance measure, Meyer (1994, p. 103) concludes; "The long held view of what gets measured gets done has spurred managers to react to intensifying competition by piling more and more measures on their operations in a bid to encourage employees to work harder. As a result, team members end up spending too much time collecting data and monitoring their activities and not enough time managing".

\section{References}

Adcroft, A. and Willis, R. (Autumn 2002) Looking in the Wrong Direction in Critical Quarterly (Tate Modern) Volume 44, No.3.

Altheide, D. L. (1987) Down to Business: the commodification of non-profit social services in Policy Studies Review, volume 6, number 4. 
Audit Commission (1986) Good Management in Local Government: Successful Practices and Action, HMSO, London.

Audit Commission (1988) The Competitive Council, HMSO, London

Audit Commission (1989) Better Financial Management in Management Paper, number 3, HMSO, London

Banham, J. (1987) Doing it Better: The United Kingdom Local Authority Audit Commission in The Australian Journal of Public Administration, volume XLVI, number 2.

Bevir, M., Rhodes, A.W. and Weller, P. (2003) Traditions of Governance: Interpreting the changing role of the public sector in Public Administration, volume 81, number 1.

Boland, T. and Fowler, A. (2000) A systems perspective of performance management in public sector organisations in The International Journal of Public Sector Management, volume 13, number 5 .

Bottery, M. and Wright, N. (2000) Teachers and the State: towards a directed profession, Routledge, London.

Bovaird, T. and Davis, P. (1999) Learning to Manage within Limited Resources: coping strategies and learning breakthroughs in UK local government in The International Journal of Public Sector Management, volume 12, number 3

Christensen, M. and Yoshimi, H. (2001) A Two Country Comparison of Public Sector Performance Reporting: The tortoise and hare? in Financial Accountability and Management, volume 17, number 3.

Deem, R. (2004) The Knowledge Worker, the Academic Manager and the Contemporary UK University: New and old forms of public management? in Financial Accountability and Management, volume 20, number 2.

Department for Education and Skills (2002) White Paper on the Future of Higher Education, HMSO, London.

Department of Health (2000) The NHS Plan, HMSO, London

de Vries, K. (1977) The Entrepreneurial Personality: A person at the crossroads in Journal of Management Studies, February.

Drucker, P. F. (1995) The Information Executives Truly Need in Harvard Business Review, volume 73 , issue 1.

Eccles, R. (1991) The Performance Measurement Manifesto in Harvard Business Review, volume 69 , issue 1.

Ferlie, E., Pettigrew, A., Ashburner, L. and Fitzgerald, L. (1996) The New Public Management in Action, Oxford University Press, UK.

Ferlie, E. and Steane, P. (2002) Changing Developments in NPM in The International Journal of Public Administration, volume 25, number 12.

Flynn, N. (1995) The future of public sector management in The International Journal of Public Sector Management, volume 8, number 4.

Gilchrist, A. (2003) Reforming the Fire Service in Public Money and Management, October.

Holloway, J., Francis, G. and Hinton, M. (1999) A vehicle for change? A case study of performance improvement in the "new" public sector in The International Journal of Public Sector Management, volume 12, number 4.

Hood, C. (1991) A Public Management for All Seasons in Public Administration, Spring, volume 69.

Kaplan, R. and Norton, D. (1992) The Balanced Scorecard - Measures that drive performance in Harvard Business Review, volume 70, issue 1.

Kirkpatrick, I. and Ackroyd, S. (2003) Transforming the Professional Archetype? The new managerialism in UK social services in Public Management Review, volume 5, issue 4.

Labour Party (1997) Because Britain Deserves Better, Labour Party, London. 
Lawler, J. and Hearn, J. (1995) UK Public Sector Organisations: the rise of managerialism and impact of change on social services departments in The International Journal of Public Sector Management, volume 8, number 4.

Lincoln, Y. S. (1998) Commodification and Contradiction in Academic Research in Studies in Cultures, Organisations and Societies, volume 4.

Local Government Finance Act (1982) HMSO, London.

Marcuse, H. (1964) One-Dimensional Man, Beacon, Boston, USA.

Marx, K. and Engels, F. (1848) The Communist Manifesto, Merlin Press, London (reprinted 1998).

McClelland, D. (1961) The Achieving Society, Van Nostrand, New Jersey, USA

McNulty, T. and Ferlie, E. (2002) Re-engineering Healthcare: The complexities of organisational transformation, Oxford University Press, UK.

Meyer, C. (1994) How the Right Measures Help Teams Excel in Harvard Business Review, volume 72 , issue 3.

National Health Service Executive (1998) The New NHS: A national framework for assessing performance, Department of Health, Weatherby, UK.

National Health Service (2002) Improvement, Expansion and Reform: Priorities and Planning Framework 2003 - 2006, Department of Health, London

Ness, J. and Cucuzza, T. (1995) Tapping the Full Potential of ABC in Harvard Business Review, volume 73, issue 4.

Norman, R. (2004) Recovering from a Tidal Wave: New directions for performance management in New Zealand's public sector in Public Finance and Management, volume 4, number 3.

Pollittt, C. (2003) The Essential Public Manager, McGraw Hill, UK.

Power, A. (1987) The crisis in council housing: is public housing manageable? In Work, Economy and Society, number 21.

Ritzer, G. and Walczak, D. (1988) Rationalisation and the Deprofessionalisation of Physicians in Social Forces, volume 67, number 1.

Sehested, K. (2002) How New Public Management Reforms Challenge the Role of Professionals in The International Journal of Public Administration, volume 25, number 12.

Simons, R. and Davila, A. (1998) How high is your return on management? in Harvard Business Review, volume 76, issue 1.

Sprigings, N. (2002) Delivering Public Services Under the New Public Management: The case of public housing in Public Money and Management, October-December.

Talib, A.A. (2004) The Offspring of New Public Management in English Universities: Accountability, performance measurement, goal setting and the prodigal child the RAE in Public Management Review, volume 5, issue 4.

The Quality Assurance Agency for Higher Education (2000) Subject Review Handbook: September 2000 to December 2001, QAAHE, Gloucester.

The Quality Assurance Agency for Higher Education (2002) Annual Report, QAAHE, Gloucester.

The Treasury (2001) Public Service Agreement Frameworks, HMSO, London.

The Treasury (2002a) The Budget Report, HMSO, London.

The Treasury (2002b) The NHS Public Service Agreement, HMSO, London

Walshe, K. and Sheldon, T.A. (1998) Dealing with Clinical Risk: Implications of the rise of evidence based healthcare in Public Money and Management, October-December.

Walshe, K. (2001) Don't try this at home: Health policy lessons for the NHS from the United States, Institute of Economic Affairs, Blackwell Publishers, UK. 
Walshe, K. and Rundall, T.G. (2001) Evidence-based Management: From theory to practice in healthcare in The Milbank Quarterly, Volume 79, number 3.

Wanless, D. (2000) Securing our Future Health: Taking a long term view, HMSO, London.

Weber, M. (1927) General Economic History, Transaction Books, Oxford (reprinted 1981).

Williams, K., Haslam, C., Williams, J. and Johal, S. (1993) Deconstructing Car Assembler Productivity in The International Journal of Production Economics, July. 